\title{
Retinal capillary malformation
}

INSERM

\section{Source}

INSERM. (1999). Orphanet: an online rare disease and orphan drug data base. Retinal capillary malformation. ORPHA:71213

Retinal cavernous hemangioma is a rare, benign, usually unilateral retinal vascular hamartoma that in most cases is asymptomatic but in some patients may present with blurred vision or floaters and that is characterized by the presence of grape-like vacuoles. 